\title{
The First Case of Successful Bark Implantation of a 250-year-old Zelkova Tree Heavily Damaged by Artificial Girdling
}

*Corresponding author

Tel: $+82-61-750-3865$

Fax: +82-61-750-3208

E-mail:youngjin@sunchon.ac.kr ORCID

https://orcid.org/0000-0002-3013-1154

Received August 10, 2018

Revised August 14, 2018

Accepted August 14, 2018

\author{
Seong Ho Ryu ${ }^{1}$, Gyoung Hee $\mathrm{Kim}^{2}$, and Young Jin Koh ${ }^{2 *}$ \\ ${ }^{1}$ Dream Landscape, Sunchang 56035, Korea \\ ${ }^{2}$ Department of Plant Medicine, Sunchon National University, Suncheon 57922, Korea
}

\begin{abstract}
A circular bark with a $30 \mathrm{~cm}$ width was artificially removed from the trunk of a 250-year-old zelkova tree (Zelkova serrata) heavily damaged by artificial girdling in Sunchang, Jeonbuk Province in March of 2005. The debarked area was cleaned approximately 10 days after artificial girdling and bark margins with $2 \mathrm{~cm}$ width above and below the girdled portion were cut off to promote wound callus formation. Nine pieces of fresh bark (width $8 \mathrm{~cm}$, length $35 \mathrm{~cm}$, thickness $0.5 \mathrm{~cm}$ ) were then prepared from branches of neighbor zelkova trees broken by heavy snowfalls and pasted onto the girdled portion of the tree, after which a Vaseline dressing was applied to water-proof the area and rubber bars were used to hold the implants to the trunk. Two pieces of the implanted fresh barks were successfully grafted onto the girdled area and the damaged tree has been vigorously growing over 13 years. To our knowledge, this is the first case of successful bark implantation to cure a 250 -year-old zelkova tree heavily damaged by artificial girdling. This bark implantation technique will be utilized for the conversation and management of heavily damaged big and old trees in the future.
\end{abstract}

Keywords: Bark implantation, Girdling, Zelkova tree
Various kinds of wounds occur on trees, usually as a result of abiotic agents such as snowfall, lightening and sunscald, or in response to anthropogenic activities. When the size of a bark wound is less than $25 \%$ of the branch girth, the wound heals by itself and does not cause permanent damage to the wounded tree. However, when the size of the bark wound is greater than $50 \%$ of the branch girth, some of the branches undergo debarking, after which the health of the entire tree suddenly declines, eventually resulting in death (Lee et al., 2017). Therefore, bark girdling has traditionally been used in silviculture in temperate areas as a means of thinning or controlling non-valuable trees (Reque and Bravo, 2007).

When a tree is heavily damaged by cutting or debarking,

Research in Plant Disease

pISSN 1598-2262, elSSN 2233-9191

www.online-rpd.org it takes several to tens of years to heal the wound even on vigorously growing zelkova trees. Moreover, when the trunk of a tree is debarked by girdling, it is important to rapidly implant fresh bark into the debarked area to treat the damaged tree (Lee, 2015).

Seven zelkova (Zelkova serrata) trees that are over 250 years of age are growing in Daesan-ri, Jeokseong-myeon, Sunchang-gun, Jeonbuk Province (Fig. 1A). One of their trunks was severely damaged by artificial girdling in late March of 2005. The trunk $1.5 \mathrm{~m}$ high above ground level was girdled with a width of $30 \mathrm{~cm}$ (Fig. 1B, C) and a southern part of the trunk was totally debarked from root-collar to $1.5 \mathrm{~m}$ high above ground level (Fig. 1D). A farmer of a neighbor paddy field intentionally girdled the bark, after which herbicide was applied to the wound to kill the zelkova tree because it caused shade on his paddy field, thereby hindering rice harvest. Since the heavily damaged tree could not be 


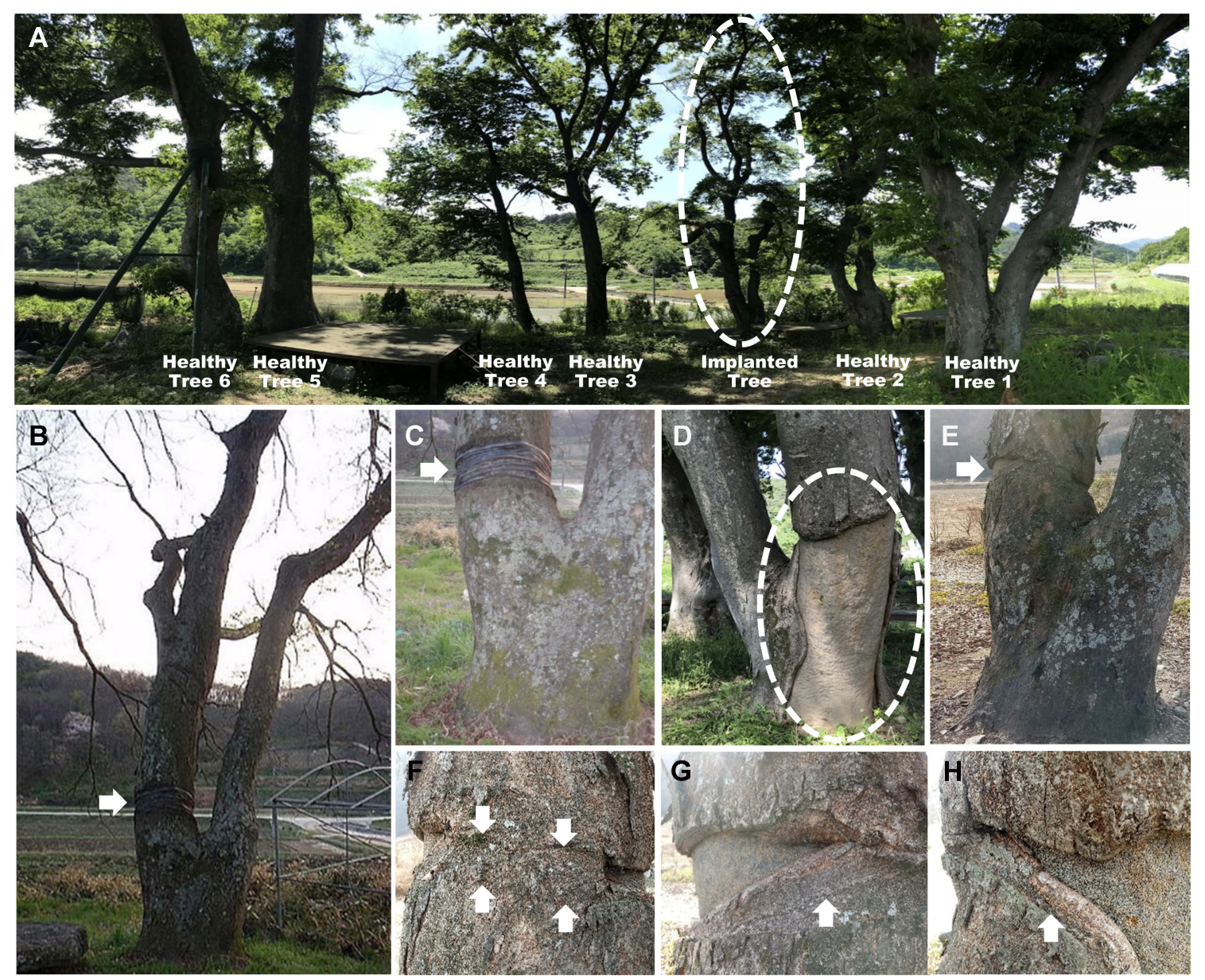

Fig. 1. Healthy and implanted zelkova trees. (A) Panorama photograph of seven big and old zelkova trees grown in Daesan-ri, Jeokseongmyeon, Sunchang-gun, Jeonbuk Province in May, 2018 (circle indicates the implanted tree), (B) Implanted zelkova tree in March, 2005 (arrow indicates the implanted part of trunk), (C) Implanted trunk in March, 2005 (arrow indicates rubber bars holding fresh barks onto the debarked trunk of the implanted tree), (D) Southern part of the implanted trunk totally debarked from root-collar to $1.5 \mathrm{~m}$ high above ground level (circle indicates surgically treated part of the debarked trunk), (E) Implanted trunk in March, 2007 (arrow indicates trunk with a surface callus formed around the implanted barks), (F) Two pieces of successfully implanted barks settled down on the debarked part of the trunk in 2018 (arrow indicates two successfully implanted barks on the trunk), (G) Surface callus formed around the left margin of the implanted barks in 2018 (arrow indicates annual rings developed on the newly regenerated bark), $(H)$ Surface callus formed around the right margin of the implanted barks in 2018 (arrow indicates annual rings developed on the newly regenerated bark).

easily recovered by conventional tree care methods such as promoting wound callus formation on the girdled part of the trunk, bark implantation was attempted.

Heavy snowfall tends to damage on trees by breaking branches, especially in March in temperate regions that moist snowfall causes serious damage on trees by more frequently than by dry snowfall. Indeed, heavy snowfall broke the branches of neighbor zelkova trees in Sunchang in late March. Therefore, several fresh branches with $10-15 \mathrm{~cm}$ in diameter were collected from the snow-damaged zelkova trees to use for bark implantation onto the damaged zelkova tree (Fig. 2C). Specifically, nine pieces of fresh bark (width
$8 \mathrm{~cm}$, length $35 \mathrm{~cm}$, thickness $0.5 \mathrm{~cm}$ ) were cut off from the broken branches using an incisory knife and carefully prepared for implantation according to the original direction of the upper and lower parts of the branches so as not to upset the polarity of the branches and tree trunks (Fig. 2D) (Lee, 2015; Lee et al., 2017). The debarked portion of the girdled zelkova tree was cleaned and bark margins of $2 \mathrm{~cm}$ width above and below the girdled part were cut off to promote wound callus formation (Fig. 2A, B). Nine pieces of fresh barks were then pasted into the girdled portion of the damaged zelkova tree approximately 10 days after artificial girdling (Fig. 2E), after which a Vaseline dressing was applied to 


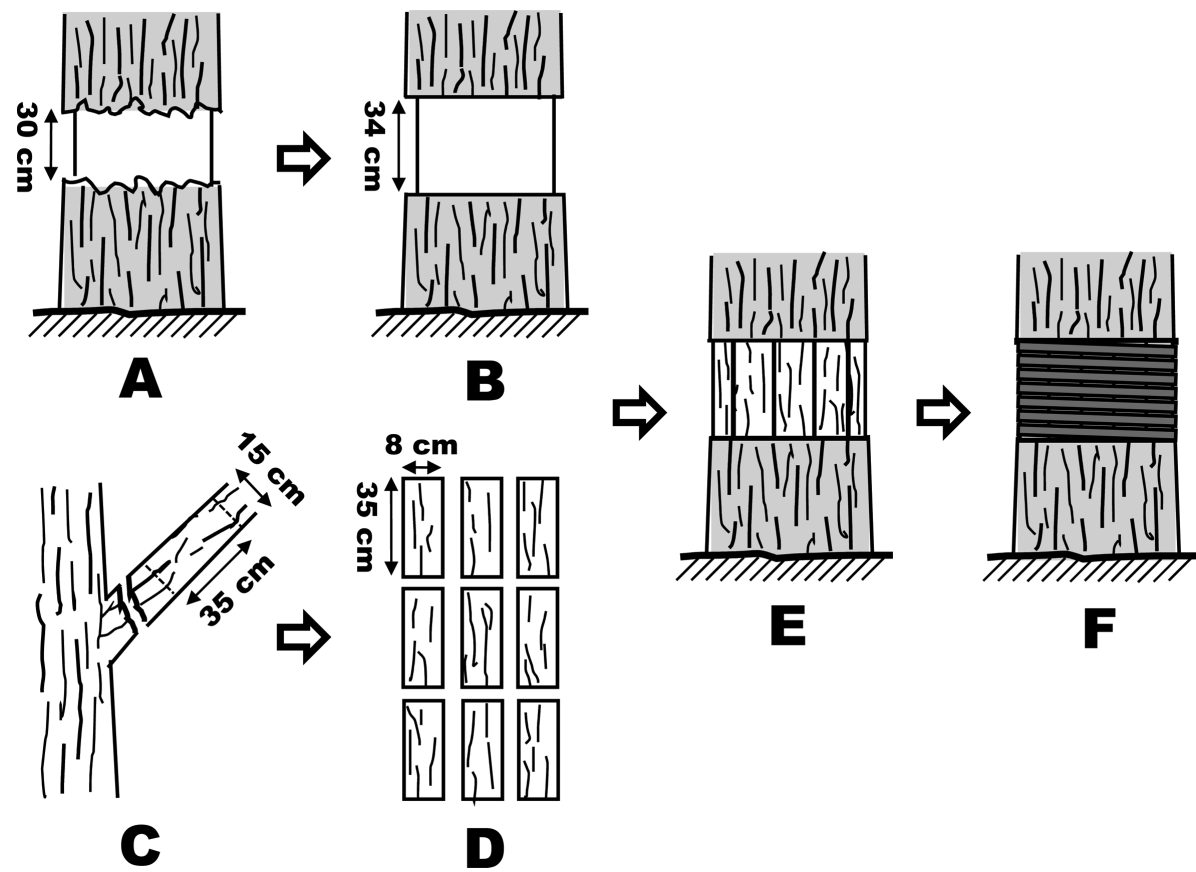

Fig. 2. Diagram of bark implantation procedure. (A) Trunk of a zelkova tree was debarked by artificial girdling with a width of $30 \mathrm{~cm}$, (B) Bark margins of $2 \mathrm{~cm}$ width above and below the girdled part were cut off and cleaned, (C) Several fresh branches with 10-15 cm in diameter were collected from the snow-damaged zelkova trees, (D) Nine pieces of fresh barks (width $8 \mathrm{~cm}$, length $35 \mathrm{~cm}$, thickness $0.5 \mathrm{~cm}$ ) were cut off from the broken branches using an incisory knife and carefully prepared for implantation according to the original direction of the upper and lower parts of the branches, (E) Nine pieces of fresh barks were pasted into the girdled portion, (F) Vaseline dressing was applied to water-proof the area and rubber bars were used to hold the implant to the trunk.

water-proof the area and rubber bars were used to hold the implant to the trunk (Fig. 1C, 2F). The other debarked part of the trunk was undergone surgical operations to prevent decay caused by any secondary infection according to routine methods (Kang, 2018; Lee, 2015).

Wood-decaying fungi easily infect wounded trunk and accelerate decay on the tree. Therefore, wounds should be dressed using proper materials to prevent decay and wrapped using polyethylene plastic to promote callus formation (McDougall and Blanchette, 1996; Shigo and Shortle, 1983). Accordingly, Vaseline was used as a wound dressing material to protect against water and sunshine exposure and rubber bars were used to fix implanted barks onto the debarked area and promote callus formation in this study (Fig. $1 \mathrm{C}, 2 \mathrm{~F})$.

The development of a surface callus is usually clearly divided into three stages: parenchyma cell formation, wound periderm formation in the outer callus and wound cambium formation in the inner tissue. The surface callus is only fully developed when this wound cambium has formed. It took 8-11 weeks until formation of the wound cambium was complete and 13-16 weeks until wound xylem and phloem were laid down by the wound cambium on lime trees (Stobbe et al., 2002). Callus formation and new bark regeneration were observed between two pieces of implanted fresh barks and the debarked part of the trunk of the damaged zelkova tree by girdling four months after bark implantation in this study.

Bark implantation should be conducted as soon as possible after girdling, and is most successful during spring, when cells vigorously divide in the cambium (Lee et al., 2017; Lee, 2017; Perry and Hickmam, 1987). Bark implantation was conducted in late March, 2005, but approximately 10 days after artificial girdling in this study. Therefore, we found that

Table 1. Result of implantation of fresh barks onto the girdled portion of the heavily damaged zelkova tree approximately 10 days after artificial girdling in late March, 2005

\begin{tabular}{|c|c|c|c|}
\hline \multicolumn{3}{|c|}{$\begin{array}{l}\text { No. of fresh bark }(8 \times 35 \mathrm{~cm}) \text { used for bark } \\
\text { implantation }\end{array}$} & \multirow{2}{*}{$\begin{array}{c}\text { \% Successful } \\
\text { bark } \\
\text { implantation }\end{array}$} \\
\hline Implanted & Grafted & Failed & \\
\hline 9 & 2 & 7 & 22.2 \\
\hline
\end{tabular}


Table 2. Comparison of cambial electrical resistance in the implanted zelkova tree and six neighbor healthy zelkova trees in May 19,2018

\begin{tabular}{|c|c|c|c|c|c|}
\hline \multicolumn{2}{|c|}{ Zelkova trees } & Trunks & $\begin{array}{l}\text { Root-collar } \\
\text { caliper }(\mathrm{cm})\end{array}$ & $\begin{array}{l}\text { Diameter at breast } \\
\text { height }(\mathrm{cm})\end{array}$ & $\begin{array}{c}\text { Relative values representing degrees } \\
\text { of cambial electrical resistancea }\end{array}$ \\
\hline \multirow{2}{*}{\multicolumn{2}{|c|}{ Implanted tree }} & Implanted & \multirow{2}{*}{342} & 213 & $91.1 \mathrm{a}$ \\
\hline & & Healthy & & 169 & $90.8 \mathrm{a}$ \\
\hline \multirow{8}{*}{ Healthy trees } & \multirow{2}{*}{1} & A & \multirow{2}{*}{545} & \multirow{2}{*}{397} & $90.4 \mathrm{a}$ \\
\hline & & B & & & $92.5 \mathrm{a}$ \\
\hline & \multirow{2}{*}{2} & $A$ & \multirow{2}{*}{394} & \multirow{2}{*}{376} & $92.0 \mathrm{a}$ \\
\hline & & $\mathrm{B}$ & & & $91.8 \mathrm{a}$ \\
\hline & \multicolumn{2}{|r|}{3} & 315 & 235 & $90.2 \mathrm{a}$ \\
\hline & \multicolumn{2}{|r|}{4} & 246 & 160 & $92.8 \mathrm{a}$ \\
\hline & \multicolumn{2}{|r|}{5} & 712 & 433 & $90.7 a$ \\
\hline & \multicolumn{2}{|r|}{6} & 451 & 326 & $91.1 \mathrm{a}$ \\
\hline
\end{tabular}

${ }^{a}$ Each number is an average of 4 replicates of relative values representing degrees of cambial electrical resistance in trunks at $200 \mathrm{~cm}$ height measured by a JunsMeter. The values higher than 86 indicate that the trees are very healthy according to the JunsMeter1's manual (Purum Bio, Korea). Same letter in the column indicates no significant difference according to the Duncan's multiple range test at $p<0.05$.

only $22.2 \%$ of the implanted fresh barks ( 2 out of 9 pieces of implanted barks) were successfully settled down on the debarked part two years after bark implantation in 2007 (Fig. 1E, $F$ and Table 1). If bark implantation had been conducted as quickly as possible, more than $22.2 \%$ of the implanted fresh barks might have been successfully grafted on the debarked part.

We can see that a surface callus was clearly formed around the implanted barks on the trunk (Fig. 1E, F) and approximately 13 annual rings were formed on the new regenerated barks on the implanted zelkova tree (Fig. 2G, H). Relative values representing degrees of cambial electrical resistance has been used for estimation of tree vigor using a JunsMeter (Lee, 2015) and tree vigor maintained maximum in May through August (Lee et al., 1997). There was no significant difference of the values among the trunks of implanted zelkova tree and six neighbor healthy zelkova trees irrespective of their ages or diameters of trunks at breast height, when we estimated tree vigor by a JunsMeter1 in May 19, 2018 (Table 2). The values obtained from the implanted trunk at $2 \mathrm{~m}$ height indicates that the implanted zelkova tree is growing as vigorously as six neighbor healthy zelkova trees 13 years after bark implantation on the debarked trunk at $1.5 \mathrm{~m}$ height, because the values higher than 86 was measured from very healthy trees according to the JunsMeter1's manual (Purum Bio, Korea). To our knowledge, this is the first case of successful bark implantation to cure a 250-year-old zelkova tree heavily damaged by artificial girdling. This bark implantation technique will be utilized for the conservation and management of heavily damaged big and old trees in the future, because Zelkova tree is the most popular among the protected old trees which hold a sustained function as natural and cultural resources in rural area in Korea ( $\mathrm{Ha}$ and Bang, 2005; Kang et al., 2011).

\section{Conflicts of Interest}

No potential conflict of interest relevant to this article was reported.

\section{References}

Ha, T. J. and Bang, K. J. 2005. A study of vitality measurements of the natural monuments - focused natural monuments Zelkova in Kyongsangdo. J. Korea Soc. Environ. Restor. Technol. 8: 100-107. (In Korean)

Kang, B. H., Cho, S. J., Son, J. K., Kim, M. H. and Ahn, O. S. 2011. A study on the management plan by actual condition survey of protected tree in Yesan-gun. J. Korean Soc. Rural Plan. 17: 67-80. (In Korean)

Kang, J. Y. 2018. Tree Surgical Operation. Haksulpyeonsugwan, Bucheon, Korea. 153 pp. (In Korean)

Lee, J. K., Cha, B. J., Shin, H. D., Na, Y. J., Kim, K. W., Kim, M. S. et al. 2017. Forest and Shade Tree Pathology. Hyangmunsa, Seoul, Korea. 342 pp. (In Korean)

Lee, K. J. 2015. Arbormedicine. SNU Press, Seoul, Korea. 468 pp. 
(In Korean)

Lee, K. J., Han, S. H. and Jeong, Y. S. 1997. Differences between species and seasonal changes in cambial electrical resistance of twenty ornamental tree species. J. Korean For. Soc. 86: 415-421. (In Korean)

McDougall, D. N. and Blanchette, R. A. 1996. Polyethylene plastic wrap for tree wounds: a promoter of wound closure on fresh wounds. J. Arboric. 22: 206-210.

Perry, E. and Hickmam, G. 1987. Wound closure in Eucalyptus. J.
Arboric. 13: 201-202.

Reque, J. A. and Bravo, F. 2007. Viability of thinning sessile oak stands by girdling. Forestry 80: 193-199.

Shigo, A. L. and Shortle, W. C. 1984. Wound dressings: results of studies over 13 years. J. Arboric. 8: 193-210.

Stobbe, H., Schmitt, U., Eckstein, D. and Dujesiefken, D. 2002. Development stages and fine structure of surface callus formed after debarking of lime trees (Tilia sp.). Ann. Bot. 89: 773-782. 